\title{
Store and release cover water balance for the south waste rock dump at Century mine
}

\author{
TK Rohde EMM Consulting Pty Limited, Australia \\ PL Defferrard MMG Limited, Australia \\ M Lord MMG Limited, Australia
}

\begin{abstract}
In 2010 a store and release cover (the cover) was constructed on the south waste rock dump (SWRD) at Century mine (the mine). The purpose of the cover is to reduce seepage (percolation) into the potentially acid forming (PAF) waste rock by maintaining a compacted reduced permeability layer (RPL) at near-saturated conditions. This is achieved by overlaying the RPL with a 1.5 to $2 \mathrm{~m}$ thickness of dolomite rock and soil-mulch (the soil-mulch). The RPL is the trafficked surface of the SWRD. The soil-mulch has a hummocky final surface that captures rainfall so it does not runoff, allowing it in part to infiltrate, with excess water removed by evaporation and transpiration. The unsaturated behaviour of the cover is being monitored by instrumentation including volumetric water content sensors and a weather station capable of estimating potential evapotranspiration. The instrumentation allows for the calculation of storage of rainfall in the cover, seepage (or percolation) through the base of the cover and in situ soil water characteristic curves (SWCC). The paper presents the results of three years of monitoring. It shows that seepage is about $6 \%$ of the total rainfall over the monitoring period and that the majority of the infiltration is going into storage within the cover before being removed by evapotranspiration. The paper presents a preliminary water balance for the cover by calibrating a Vadose/w model (the model) using in situ SWCCS and calculating actual evapotranspiration.
\end{abstract}

\section{Introduction}

The south waste rock dump (SWRD) at Century mine (the mine) was commissioned in 1998 and received both potentially acid forming (PAF) and non-acid forming (NAF) waste rock. The SWRD has produced near-pneutral high salinity seepage throughout its operational life. In 2010 the SWRD was decommissioned and a store and release cover (the cover) was constructed to limit future infiltration. Limiting infiltration will reduce long-term saline seepage.

\subsection{Site location}

The mine is located $250 \mathrm{~km}$ north-northwest of Mount Isa, Queensland, Australia. The topography of the site comprises of undulating hills and ridgelines. The site vegetation is low and sparse, as is typical of the semi-arid environment of northern Australia.

\subsection{Climate}

Rainfall data is available from the Bureau of Meteorology (BoM) weather station (Century mine: station 029167). The average annual rainfall is $544 \mathrm{~mm}$, with a dry season from April to September and a wet season from October to March. January and February account for about $50 \%$ of total rainfall.

The combined effect of evaporation and transpiration (evapotranspiration) at the mine is about five times greater than rainfall. The Global Acid Rock Drainage (GARD) Guide (2009) suggests that a cover might be an effective tool, in combination with other methods, to reduce the potential for uncontrolled release of saline seepage to the receiving environment. 


\subsection{Intention of paper}

Covers that store rainfall for subsequent release as evaporation or transpiration (store and release cover) is not a new concept and has been used within the agricultural sector for the last 45 years (Russell \& Greacen 1977). And this type of cover has inadvertently been used in the Australian mining sector for decades. Arguably, any covering of wastes performed at Australian mines functions as a store and release cover. Much of the literature related to covers has concerned itself with cover geometry with fewer papers devoted to performance including calibrating the performance of the cover so that a water balance is presented. The purpose of this paper is therefore to offer a calibrated water balance for the cover thereby adding to the collective understanding.

\subsection{Literature review}

Literature for Australia that relates to cover geometry is typically for mono or duplex layer covers. Mt Whaleback Iron Ore Mine and Peak Gold Mine exemplify mono-layer systems since only one layer is employed in the cover (Ayres et al. 2003; O'Kane et al. 2000; O'Kane \& Walters 2003). Kidston Gold Mine and Cadia Gold Mine exemplify duplex covers as the covers utilise a compacted layer (reduced permeability layer or RPL) overlain by soil-mulch (Williams et al. 1997; Durham 2002; Wilson 2000; Rohde \& Williams 2009).

Cover performance is difficult to determine from the literature with the reviewer often required to make some assumptions to estimate the performance of the cover where performance relies on the estimation of seepage percentage from the base of the cover. Some examples of seepage that has been reported in the literature include $2 \mathrm{~m}$ and $4 \mathrm{~m}$ cover options for Mt Whaleback Mine (mono-layer covers) and Kidston Gold Mine and Cadia Gold Mine (duplex layer covers), (Figure 1).

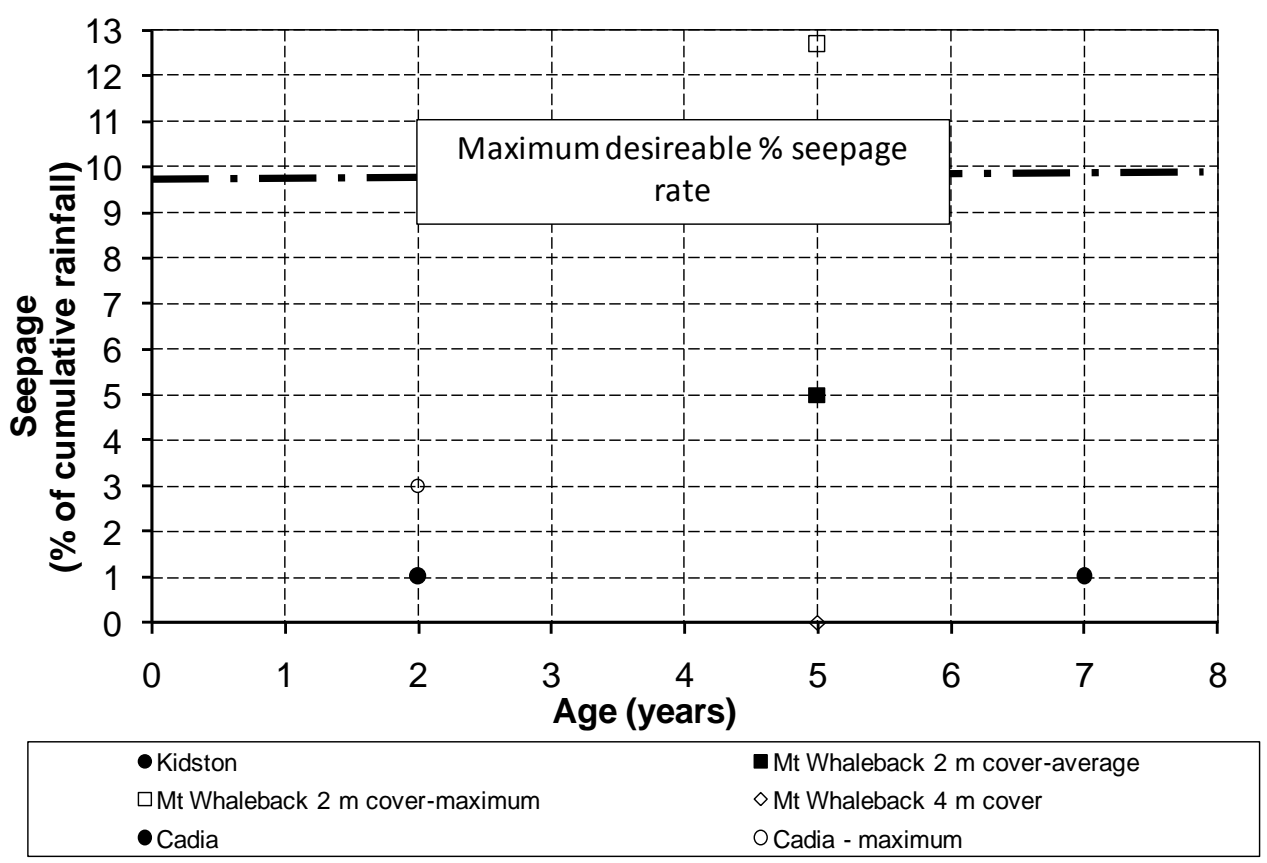

Figure 1 Performance (seepage) of Australian covers

From Figure 1 it is notable that cover performance monitoring has only been reported for short periods of up to eight years and that performance of the cover, from the estimation of seepage percentage ranges between near zero for Kidston Gold Mine (duplex layer cover) to nearly $13 \%$ for the $4 \mathrm{~m}$ cover option at Mt Whaleback Mine (mono-layer cover).

The maximum desirable percentage seepage rate shown in Figure 1 is approximately equivalent to $1 \times 10^{-8} \mathrm{~m} / \mathrm{s}$ being the approximate natural rate of groundwater recharge in semi arid Australian climates (Cook et al. 2004). 


\section{$2 \quad$ Method}

\subsection{South waste rock dump}

The SWRD was constructed from about July 1998 and was raised in three benches of 16,16 and $32 \mathrm{~m}$ to a maximum height of $64 \mathrm{~m}$. The average height of the SWRD is $55 \mathrm{~m}$ and comprises about $50.5 \mathrm{Mm}^{3}$ of acid neutralising dolomite, mainly in the base and sides; $0.9 \mathrm{Mm}^{3}$ of NAF siltstone and sandstone; and $25.9 \mathrm{Mm}^{3}$ (34\%) of PAF shale, mainly in centre of each lift (Scott \& Defferrard 2013).

The majority of the acid neutralising dolomite, which was excavated at shallow depth in the open pit, was located in the bottom bench of the SWRD, and the deeper PAF shale was placed above it. A $20 \mathrm{~m}$ wide NAF dolomite perimeter was dumped around the sides of the PAF shale benches, effectively encapsulating the PAF shale with neutralising dolomite.

Near-neutral, saline seepage occurs from the toe of the SWRD, with a pH of approximately 6.5 and total dissolved solids ranging from $7,000 \mathrm{mg} / \mathrm{L}$ during the wet season to $8,100 \mathrm{mg} / \mathrm{L}$ during the dry season. The near neutral drainage is likely a result of the neutralising affect of the dolomite pad at the base of the SWRD, however, it is not known if the effect of the dolomite pad will reduce with time as a result of the neutralising capacity being depleted.

A closure options study identified a store and release cover to prevent seepage as the preferred closure strategy for the SWRD.

\subsection{Store and release cover}

In 2010 a cover was constructed on the SWRD (Williams 2008a). The purpose of the cover is to reduce infiltration into PAF waste rock by maintaining a RPL at near-saturated conditions. This is achieved by overlaying the RPL (0.25 m thick) with a 1.5-2 m thickness of soil-mulch (Figure 2(a)). The soil-mulch has a hummocky final surface that captures rainfall, allowing it in part to infiltrate, with excess rainfall removed by evaporation, transpiration, lateral flow along the boundary between the soil-mulch and RPL (Figure 2(b)) or as seepage if percolation occurs through the RPL.

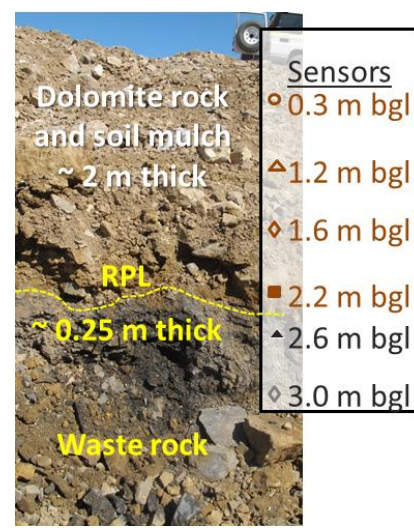

(a)

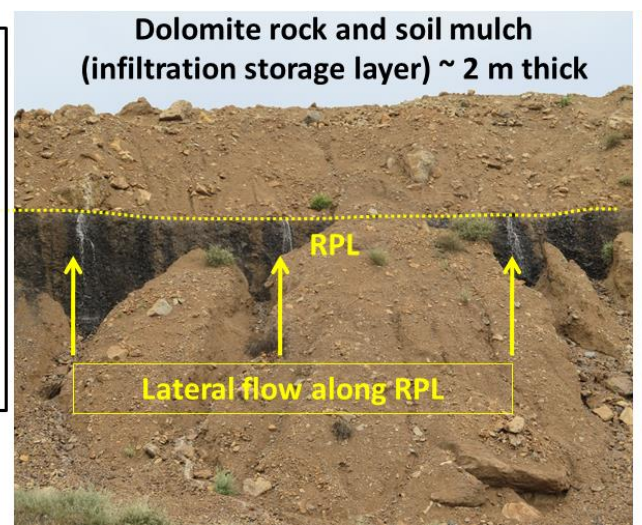

(b)

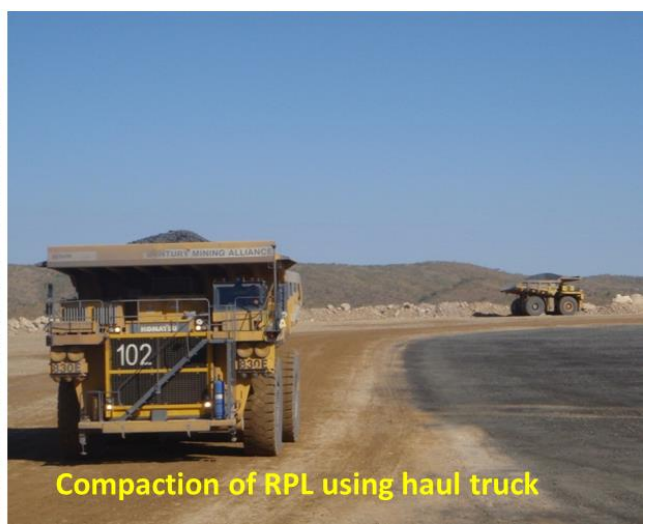

(c)

Figure 2 The store and release cover on the SWRD at Century mine: (a) cross-section; (b) lateral flow along the boundary between the soil-mulch and RPL; (c) compaction of the RPL

The RPL is novel because it is predominately the traffic compacted surface of the SWRD (Figure 2(c)). A 2008 study of the West Waste Rock Dump found that trafficking by fully loaded haul trucks (Komatsu $340 \mathrm{E})$ resulted in compaction that was up to $137 \%$ of laboratory maximum dry density and that the saturated hydraulic conductivity of the traffic compacted waste rock dump surface was about two orders of magnitude lower than the laboratory value for maximum dry density (Figure 3), (Williams 2008b). Williams (2008b) concluded that the traffic compacted surface of waste rock dumps at the mine would make a suitable RPL as part of a cover. Some sections of the compacted RPL have been constructed from 
compacted clay that became available during the construction of a nearby sediment dam. The use of compacted clay as an RPL has been used successfully in many other Australian covers (Rohde \& Williams 2009; Rohde et al. 2011; Williams et al. 2006). The thickness of the RPL varies across the SWRD but is generally thicker than $0.25 \mathrm{~m}$ (Rohde 2012). The RPL has been graded at 0.5 to $1 \%$ towards the outer batter slopes of the SWRD.

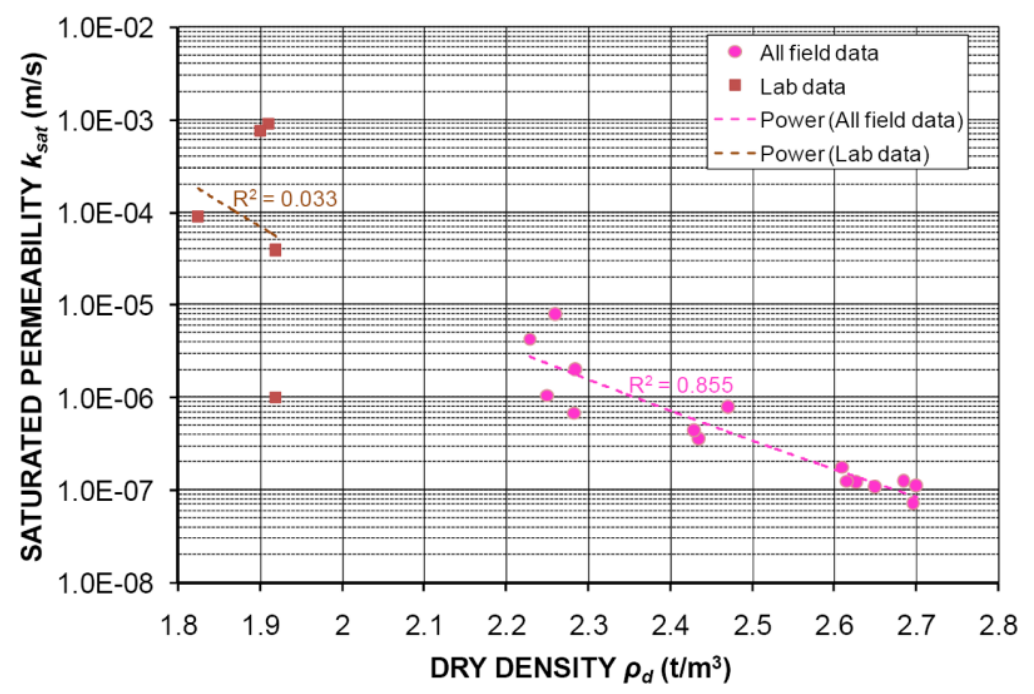

Figure 3 West Waste Rock Dump saturated permeability versus laboratory and field density

\subsection{Instrumentation}

The SWRD cover is monitored at five locations (Figure 4). A general description of the cover is provided in Section 2.1 and in Figure 2(a). Each of the five locations is instrumented with a number of instruments, including volumetric water content sensors and a weather station. This paper presents results for selected volumetric water content sensors from location one (Figure 4) for approximate depths of 0.3, 1.2, 1.6, 2.2, 2.6 and $3 \mathrm{~m}$ below ground level (bgl) (Figure 2a). Further detail on instrumentation installation methods can be reviewed in Defferrard et al. (2015).

Location one is used for analysis in this paper because the calculated seepage (discussed in Section 3.2.2) from this monitoring location is closest to the three year average calculated from all monitoring locations. Therefore, the infiltration water balance from the monitoring location is most likely to be indicative of the average result for the entire SWRD cover.

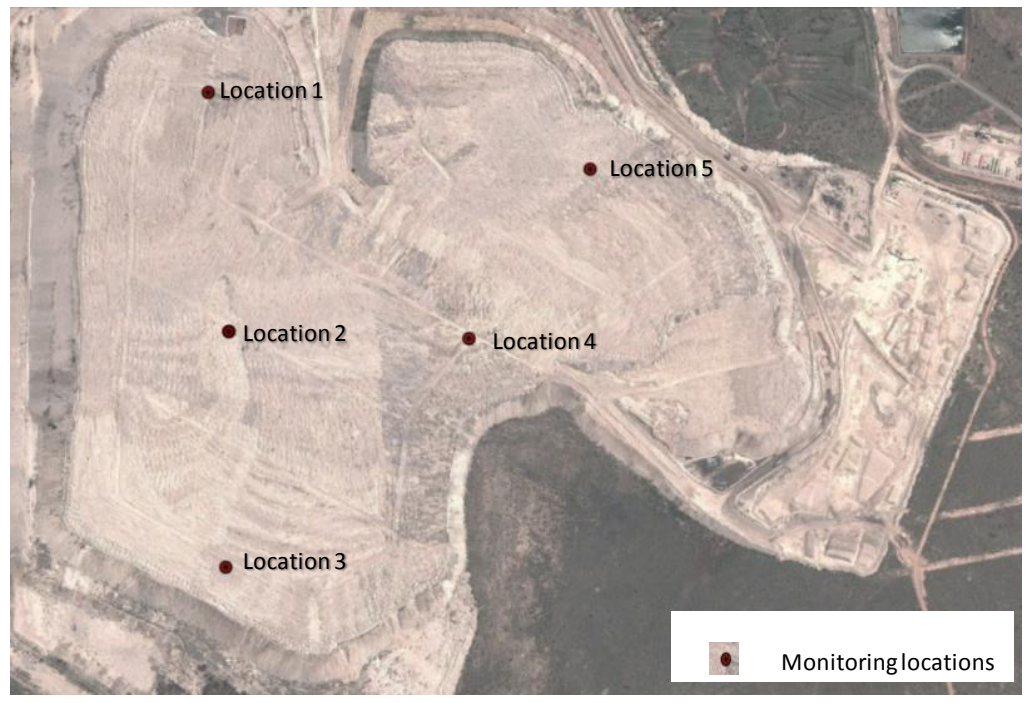

Figure 4 Instrumentation of the store and release cover on the SWRD 


\section{$3 \quad$ Results}

The cover water balance is made up of: rainfall which is measured by a weather station on the SWRD; stored infiltration which is calculated from the volumetric water content sensors; seepage which is calculated from the volumetric water content sensors and; evapotranspiration which is measured by a weather station as a potential.

\subsection{Rainfall}

In the last three years the mine has experienced lower than average annual rainfall $(544 \mathrm{~mm})$ in all three years that is: $300 \mathrm{~mm}$ in 2012-2013, $520 \mathrm{~mm}$ in 2013-2014 and, $230 \mathrm{~mm}$ in 2014-2015 (Figure 5).

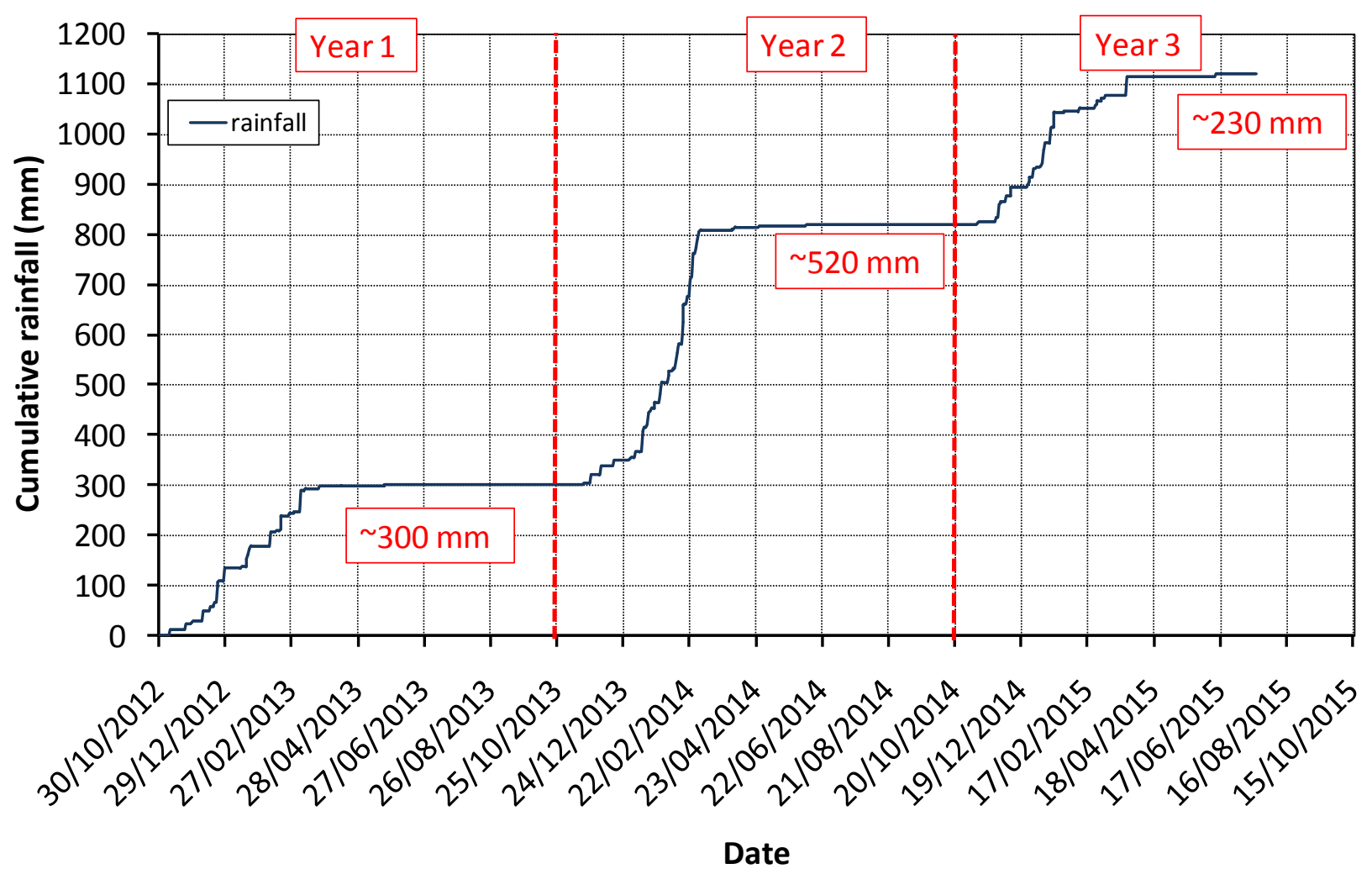

Figure 5 Cumulative and annual rainfall on the SWRD at Century mine

\subsection{Volumetric water content}

Figure 6 shows the in situ volumetric water content versus time at different depths in the soil-mulch (0.33, 1.23 and $2.23 \mathrm{~m} \mathrm{bgl}$ ), RPL and waste rock ( 2.63 and $3.03 \mathrm{~m} \mathrm{bgl}$ respectively) for location one. Figure 6 shows the volumetric water content at which the degree of saturation $(S)$ is equal to one for the cover layers. As might be expected, the cover gets wet and dries out in response to rainfall and subsequent dry periods. The base of the soil-mulch $(2.23 \mathrm{~m} \mathrm{bgl}), \mathrm{RPL}(2.63 \mathrm{~m} \mathrm{bgl})$ and waste rock beneath the RPL $(3.03 \mathrm{~m} \mathrm{bg})$ become near-saturated during the wet season in the first two years of monitoring but in the third year the RPL and waste rock beneath the RPL are not near-saturated - however the base of the soil-mulch is. The third year wetting and drying pattern is likely the result of vegetation becoming established on the cover. 

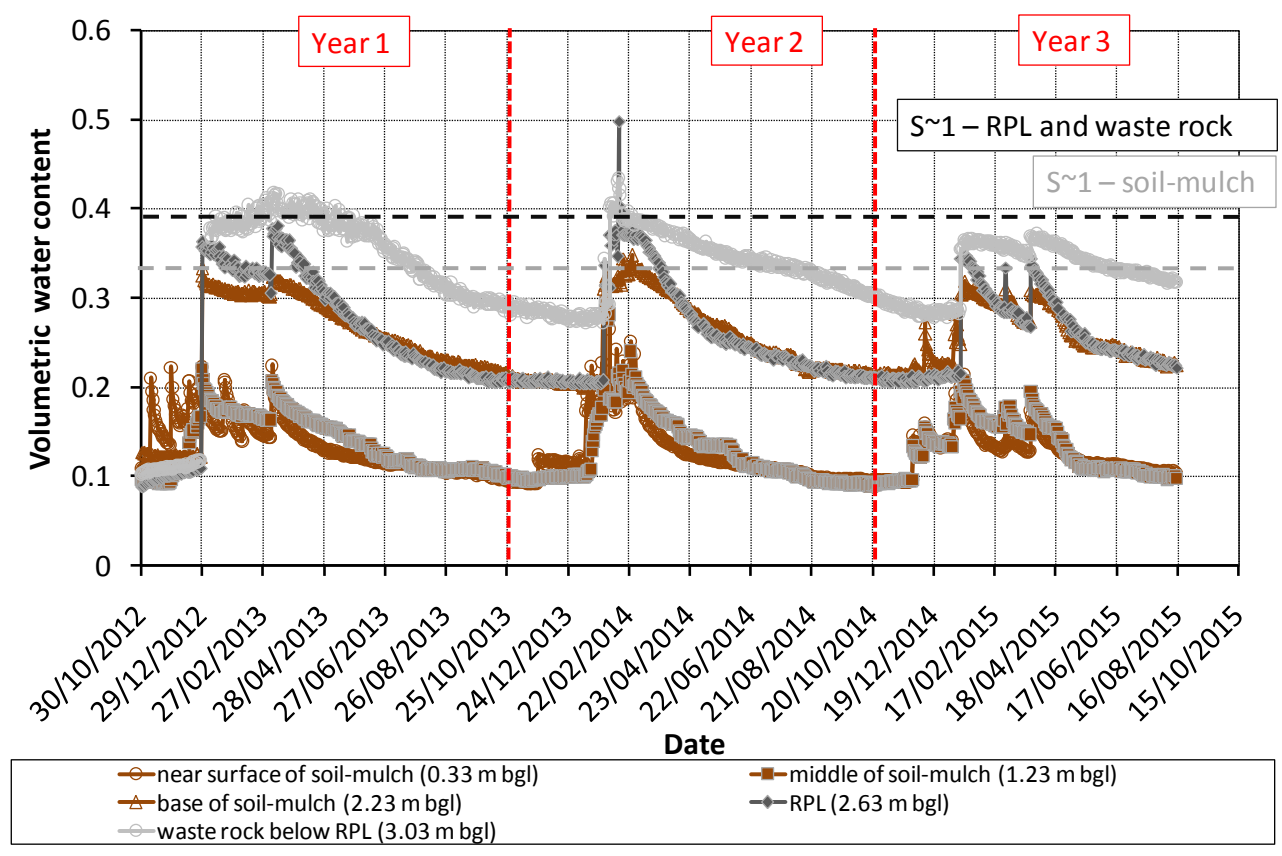

Figure 6 Volumetric water content versus time for the cover (location 1)

\subsubsection{Stored infiltration}

The stored infiltration in the cover can be calculated on a daily basis by multiplying the change in volumetric water content by depth. The daily incremental change $(\Delta)$ in stored infiltration $(\Delta S W)$ balances the infiltration budget on a daily basis as either wetting (+ve $\Delta S W$ ) or drying (-ve $\Delta S W$ ). As such, it is proportional to the rate of evapotranspiration. Figure 7 presents the stored infiltration in the cover versus time for location one. Figure 7 shows that the maximum infiltration storage is approximately $90 \mathrm{~mm}$ and corresponds to the wet season in each year. A maximum of $60 \mathrm{~mm}$ or $80 \%$ of stored infiltration is held in the soil-mulch and a maximum of $20 \mathrm{~mm}$ or $20 \%$ of stored infiltration is in the RPL.

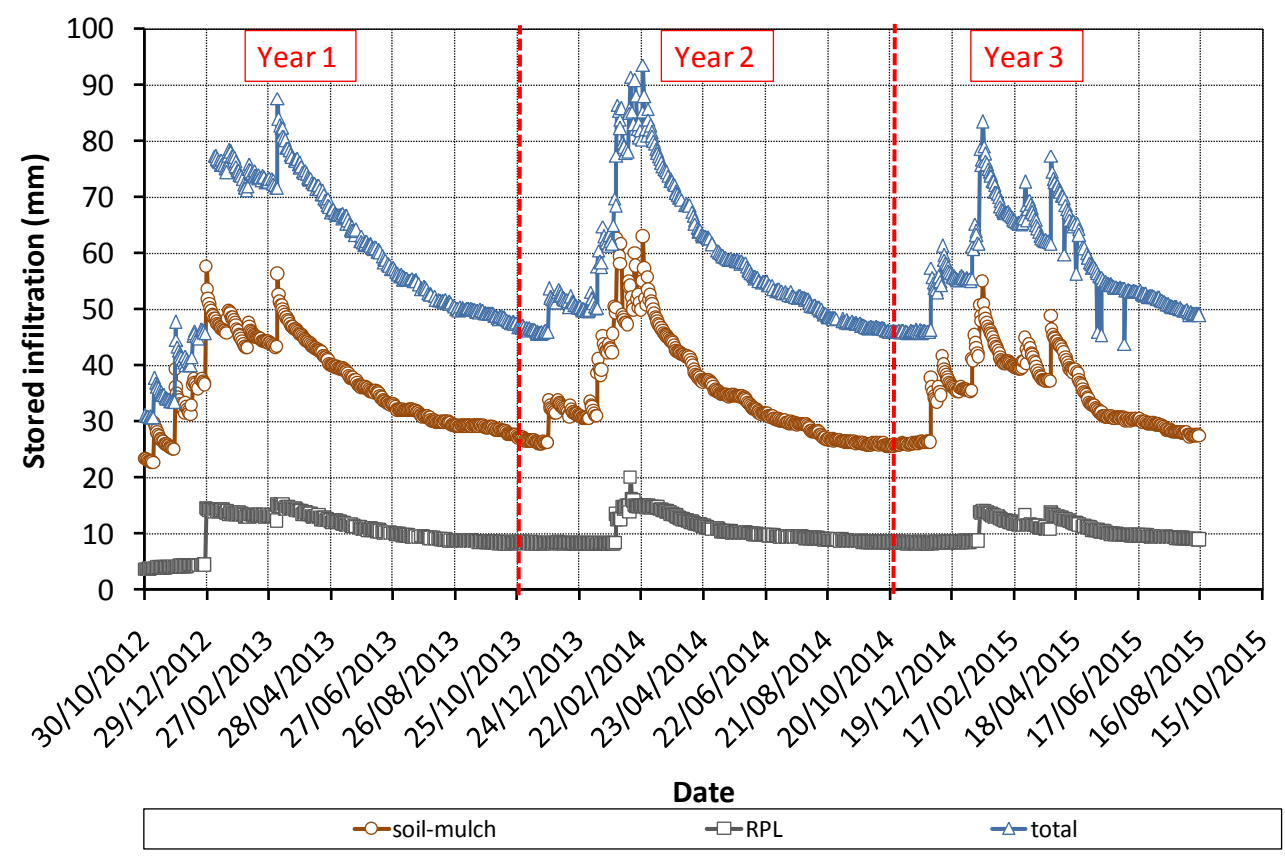

Figure 7 Storage of infiltration versus time for the cover (location 1) 


\subsubsection{Seepage}

Seepage from the cover can be calculated on a daily basis (Figure 8) by multiplying the change in volumetric water content by depth for the sensor located in the RPL $(2.63 \mathrm{~m} \mathrm{bgl})$ and the sensor located below the RPL in waste rock $(3.03 \mathrm{~m} \mathrm{bgl})$, noting that this method does not account for potential lateral flow. When the daily incremental change in $\Delta S W$ is -ve $\Delta S W$ then it is assumed that seepage is occurring because percolation is occurring across the RPL to waste rock boundary. Percolation will eventually present as seepage at the toe of the SWRD.

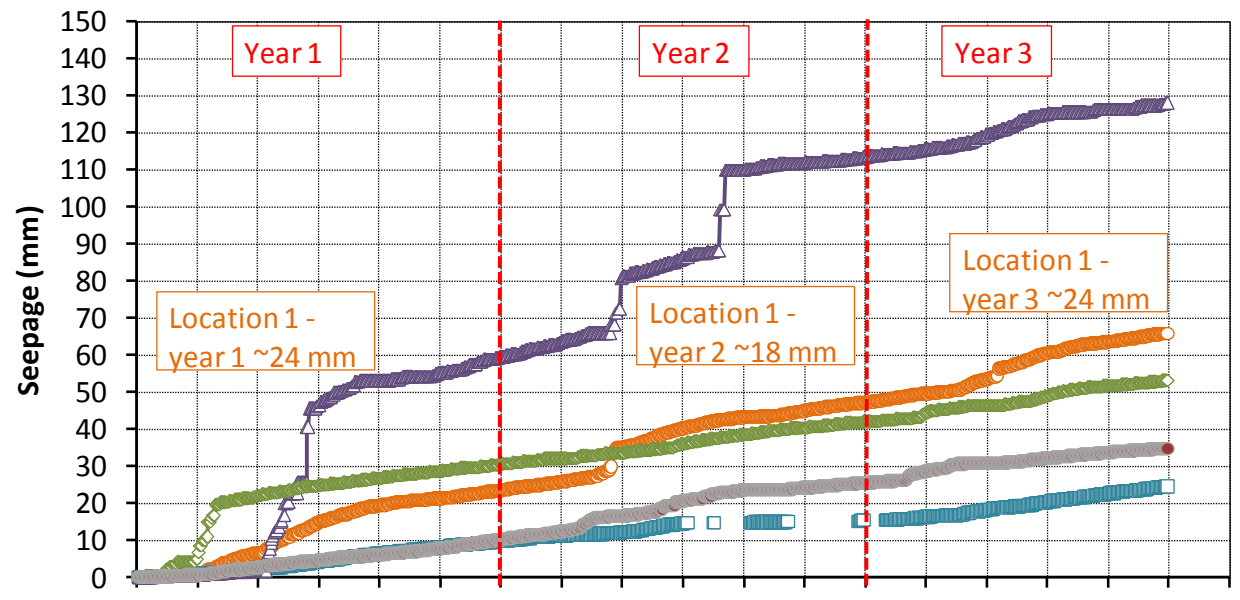

(a)
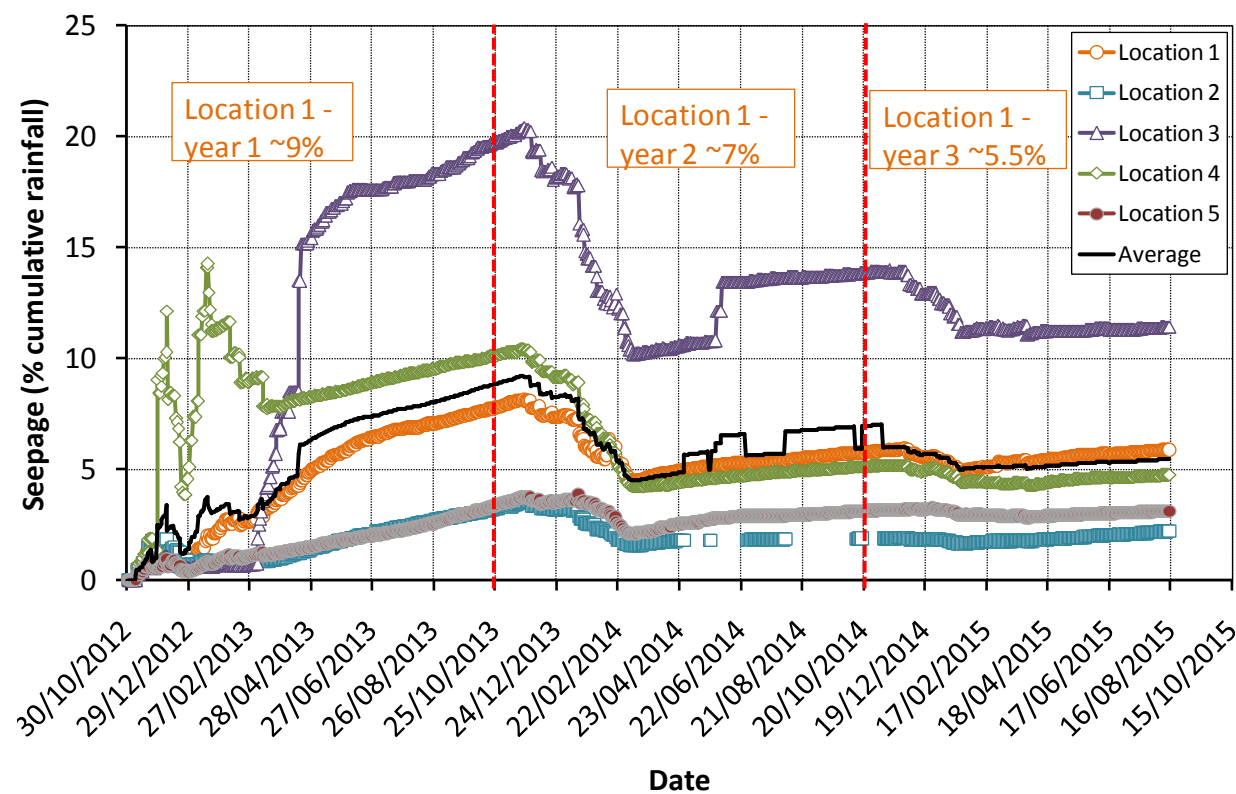

(b)

Figure 8 Seepage (percolation) versus time for the cover (all locations) (a) seepage as millimetres (b) seepage as a percentage of cumulative rainfall

Figure 8 presents the calculated seepage from the cover for all monitoring locations to show the variation in seepage across the SWRD. Figure 8 shows that the SWRD has had a wide range of seepage results since instrumentation was placed in October 2010. The first year of seepage, measured as a percentage of cumulative rainfall, shows that the cover reached a maximum seepage rate of about $20 \%$ or $60 \mathrm{~mm}$ of cumulative seepage, a minimum of about $7 \%$ or $10 \mathrm{~mm}$ of cumulative seepage and, an average, of about $9 \%$ or $24 \mathrm{~mm}$. The performance of the cover in years two and three shows a decrease in seepage. In year two the maximum seepage rate is about $14 \%$ or $110 \mathrm{~mm}$ of cumulative seepage, the minimum seepage rate is about $2 \%$ or about $17 \mathrm{~mm}$ of cumulative seepage and, on average, approximately $7 \%$ or $18 \mathrm{~mm}$ for 
the SWRD. Year three shows the best cover performance with the cover restricting seepage to a maximum of approximately $12 \%$ or $130 \mathrm{~mm}$ of cumulative seepage, a minimum of about $3 \%$ or $22 \mathrm{~mm}$ of cumulative seepage and, on average, seepage across the SWRD is approximately $5.5 \%$ or $24 \mathrm{~mm}$.

The first year of seepage from the cover is most likely a function of two variables: vegetation, which impacts on the potential evapotranspiration rate and; the fact that the cover was highly disturbed from installing the instruments. The cover performance shows a decreasing seepage trend over the three years of monitoring. The third year reduced seepage is likely the result of vegetation becoming established and the very low rainfall on the cover. The performance of location 1 is close to the average seepage as percentage of cumulative rainfall.

\subsection{Evapotranspiration}

The SWRD weather station measures the potential evapotranspiration rate using the Penman-Monteith equation using a grass reference evapotranspiration method (Allen et al. 1989; Campbell Scientific Inc. 2000). This method is derived for agricultural settings where the reference crop is defined as a short grass crop that is not stressed. That is, it assumes the soil-mulch remains near-saturated compared to the permanent wilting point ( water-entry value). The method can therefore be thought of as a theoretical maximum value. The use of this reference for the SWRD is not appropriate, where water requirements, vegetation height and cover deviate substantially from the reference crop and assumptions.

The potential evapotranspiration rate estimated from the SWRD weather station therefore must be calibrated to the unsaturated conditions of the cover, using an unsaturated soil mechanics model to provide actual evapotranspiration.

\section{Discussion}

The following section describes how actual evapotranspiration was calculated from potential evapotranspiration using Vadose/w (the model).

\subsection{Vadose/w model set-up}

The cover was modelled using the model developed by Geoslope International which is a finite element model that simulates water transport through a saturated or unsaturated medium. Derivations for saturated and unsaturated water transport can be found in Geoslope (2012).

The model was developed in one dimension and calculated the upward and downward movement of rainfall infiltration in the cover; it assumed no surface run off or run on and allowed ponding at the surface of the cover.

The model was run for location 1 since the seepage results for that location are closest to the average for the entire SWRD (Figure 8).

\subsubsection{Model dimensions}

The model was developed to replicate the cover that is, a $2 \mathrm{~m}$ thick soil-mulch layer, underlain by a $0.25 \mathrm{~m}$ thick RPL, underlain by $64 \mathrm{~m}$ thick layer of waste rock (Section 2.1 and 2.2).

\subsubsection{Mesh geometry}

The best shaped mesh elements for finite element analysis are squares or equilateral triangles. Slight deviations from these shapes, for example rectangles are also acceptable but these deviations should not be used in critical layers of the model. For this model, square and rectangle elements were used. Square elements were used in critical layers of the model including the soil-mulch and RPL. Rectangle elements were used in less critical layers of the model that is the waste rock beneath the RPL. 


\subsubsection{Initial conditions}

The model was run for a three year period using the rainfall data recorded from the SWRD weather station (Figure 5).

The model requires soil water characteristic curves (SWCC). A SWCC is the relationship between pore water and matric suction for a profile. The in situ SWCC for the soil-mulch which derived from the volumetric water content and matric suction sensors (results not presented) in the cover $(0.33,1.23$ and $2.23 \mathrm{~m} \mathrm{bgl)}$ RPL and waste rock (2.63 and $3.03 \mathrm{~m} \mathrm{bgl,} \mathrm{respectively),} \mathrm{(Figure} \mathrm{9).} \mathrm{The} \mathrm{average} \mathrm{trend} \mathrm{lines} \mathrm{for} \mathrm{the} \mathrm{soil}$ mulch, RPL and waste rock were used in the model.

The saturated hydraulic conductivity of the soil-mulch was estimated to be $0.864 \mathrm{~m} /$ day and the saturated hydraulic conductivity for the RPL and waste rock was 0.025 and $0.25 \mathrm{~m} /$ day, respectively (Williams 2008b).

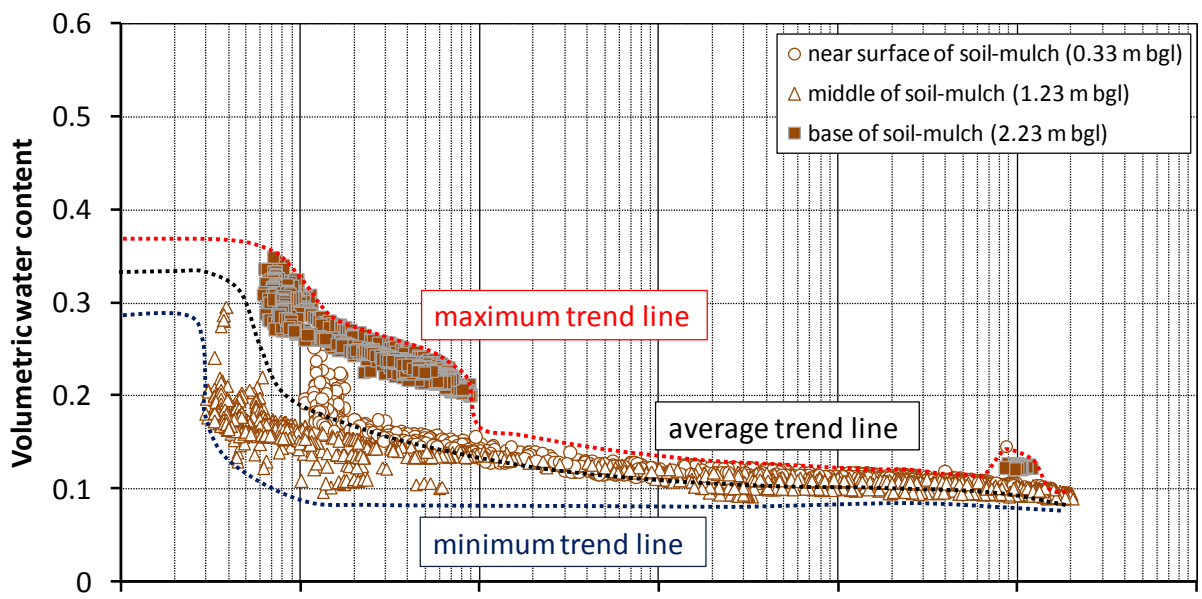

(a)

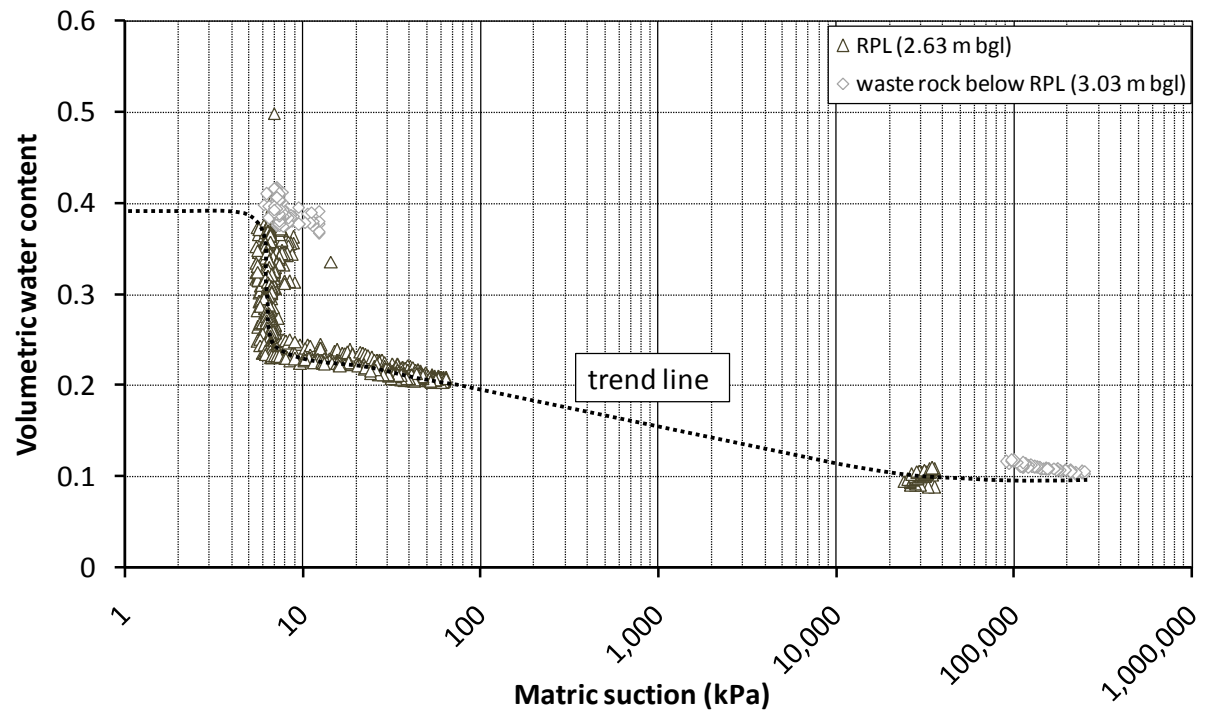

(b)

Figure 9 Soil water characteristic curves: (a) for the soil mulch and (b) the RPL and waste rock

\subsection{Vadose/w results}

The model was run for three daily evapotranspiration rates: 30,50 and $80 \%$ of the potential evapotranspiration rate measured by the SWRD weather station, assuming that a water table condition existed at the base of the modelled cross-section, that is, $66.5 \mathrm{~m} \mathrm{bgl}$. The results of the model did not produce volumetric water content ranges that were consistent with the in situ results (Section 3.2). The model was predicting that the cover would dry out to residual volumetric water content in the first three 
years (results not shown), compared to the in situ results which show that the base of the storage layer $(2.23 \mathrm{~m} \mathrm{bgl})$, the RPL $(2.63 \mathrm{~m} \mathrm{bgl})$ and the waste rock beneath the RPL ( $3.03 \mathrm{~m} \mathrm{bgl})$ remain relatively wet to near-saturated over the three years of monitoring (Figure 6). Further, the residual volumetric water contents for these layers at the end of the dry season are higher than middle $(1.23 \mathrm{~m} \mathrm{bg})$ and near surface (0.33 m bgl) of the soil-mulch (Figure 6).

Further consideration of volumetric water content trend with depth (Figure 10 (a)) and the corresponding degree of saturation (Figure 10 (b)) shows that there is an increased volumetric water content with depth correlating to a degree of saturation of between 0.7 to 1 in the soil-mulch immediately above the RPL $(2.2 \mathrm{~m} \mathrm{bg})$. It was hypothesised that the very wet condition at the base of the soil-mulch layer is acting like a perched water table. A water table was entered into the model at $2.2 \mathrm{~m} \mathrm{bgl}$ and the model was rerun for four daily evapotranspiration rates, $30,50,70$ and $80 \%$ of the potential evapotranspiration rate measured by the SWRD weather station.

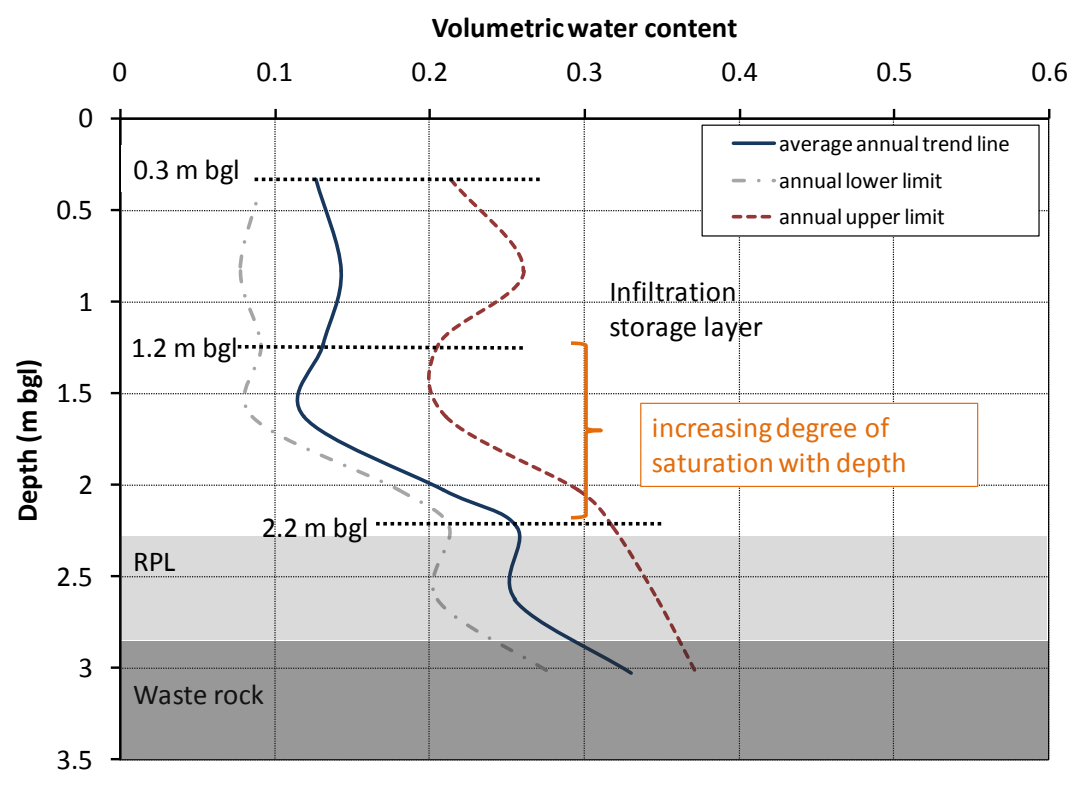

(a)

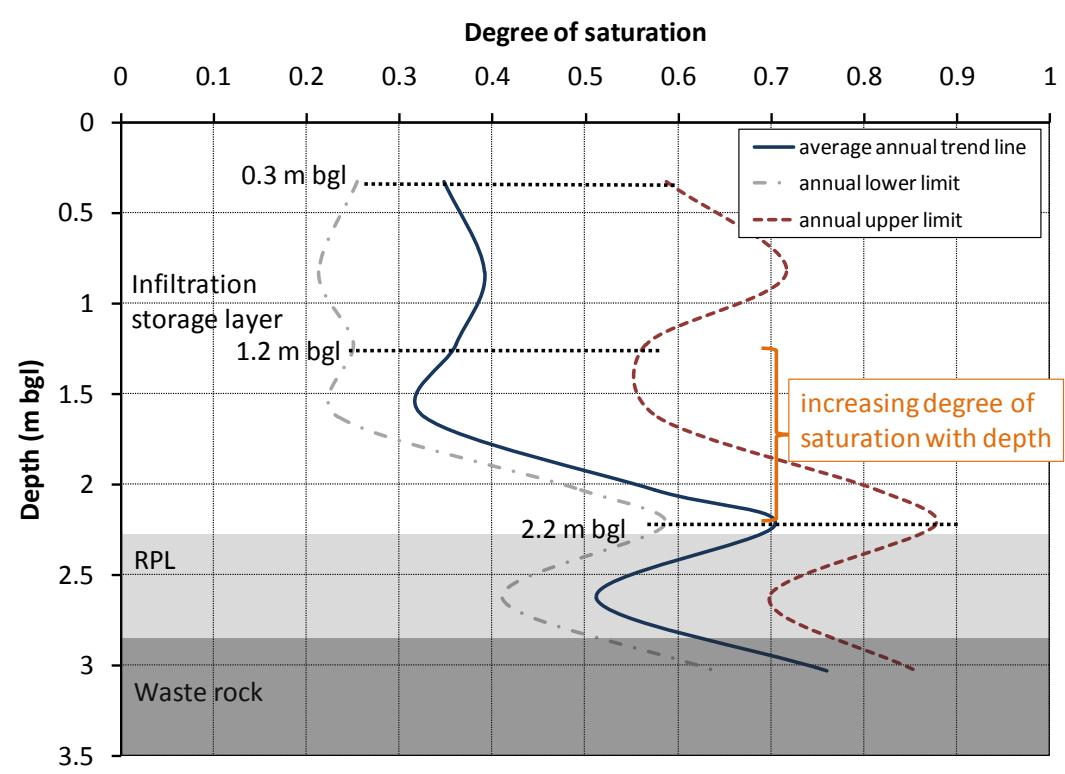

(b)

Figure 10 Measured ranges of (a) volumetric water content and (b) degree of saturation versus depth (location 1) 
Figure 11 shows the result of the model for the near surface $(0.33 \mathrm{~m} \mathrm{bgl})$ for the soil-mulch comparing the in situ measured volumetric water content to the model, assuming that there is a perched water table condition at $2.2 \mathrm{~m} \mathrm{bgl}$. The model validated the perched water table assumption and was able to predict that the actual daily evaporation rate is $80 \%$ or $2,000 \mathrm{~mm}$ of potential evaporation in year 1 , and $70 \%$ or $1,500 \mathrm{~mm}$ and $1,600 \mathrm{~mm}$ of potential evaporation in years 2 and 3, respectively (Figure 12). It should be noted that the model did not perfectly predict the in situ results (Figure 12) and it is believed that further analysis of the SWCCS would be required to improve the model prediction.
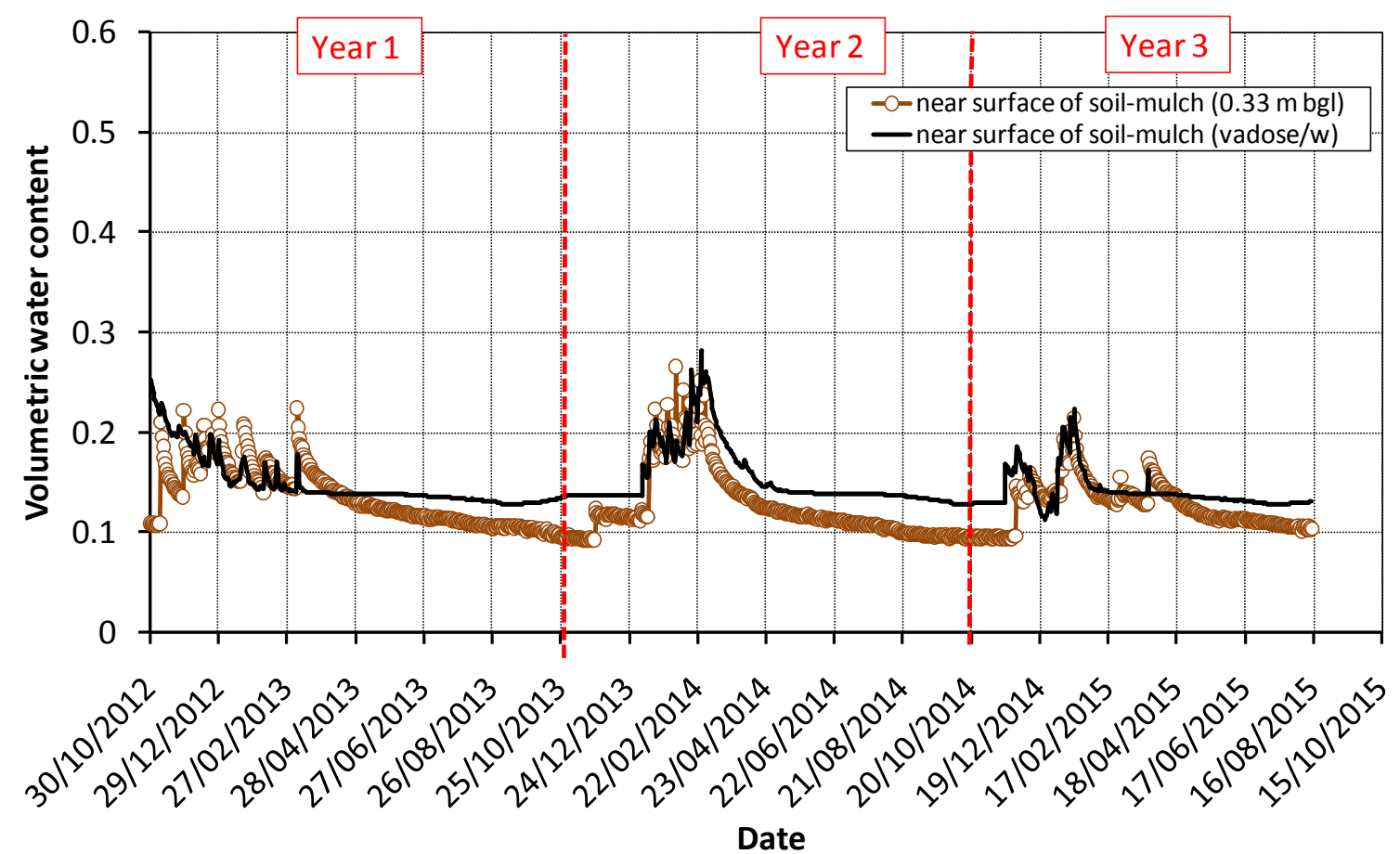

Figure 11 Volumetric water content result versus time $(0.33 \mathrm{~m}$ bgl) comparing in situ measured response to the model at the same depth (location 1)

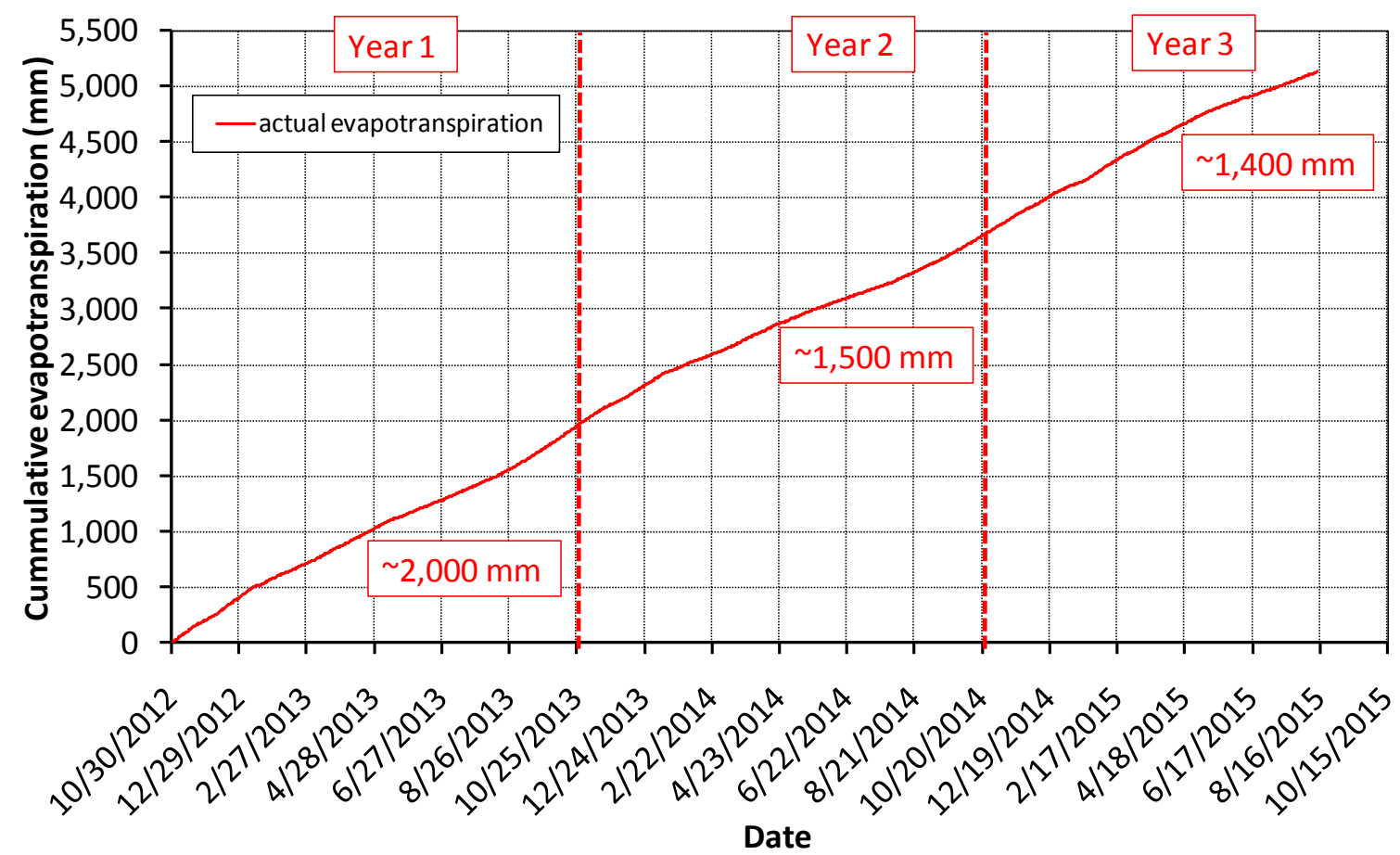

Figure 12 Cumulative actual evapotranspiration versus time (location 1) 


\subsection{Cover water balance}

The water balance for the cover is summarised in Table 1, noting that it is assumed that $100 \%$ of rainfall will initially infiltrate. Actual evapotranspiration far exceeds the mass balanced potential lateral flow plus evapotranspiration. Therefore lateral flow is likely only occurring in response to storm events where the vertical saturated hydraulic conductivity of the infiltration storage layer is quickly exceeded by the lateral saturated hydraulic conductivity resulting in infiltration flowing horizontally along the surface of the RPL before being discharged at the SWRD batter slopes. During periods of normal rainfall or during periods of no rainfall, all infiltration will initially infiltrate and then be removed by evapotranspiration with a minor amount removed by seepage ( $\leq 8 \%)$.

Table 1 Water balance (location 1)

\begin{tabular}{llll}
\hline & Year 1 & Year 2 & Year 3 \\
\hline Rainfall & $300 \mathrm{~mm}$ & $520 \mathrm{~mm}$ & $230 \mathrm{~mm}$ \\
\hline Infiltration & $100 \%$ & $100 \%$ & $100 \%$ \\
\hline Stored infiltration at end of year & $16.67 \%(\sim 50 \mathrm{~mm})$ & $8.65 \%(45 \mathrm{~mm})$ & $21.7 \%(50 \mathrm{~mm})$ \\
\hline Seepage & $8 \%(\sim 24 \mathrm{~mm})$ & $5 \%(\sim 24 \mathrm{~mm})$ & $7.8 \%(\sim 18 \mathrm{~mm})$ \\
\hline Lateral flow plus evapotranspiration ${ }^{1}$ & $75.33 \%$ & $86.35 \%$ & $70.5 \%$ \\
\hline Actual evapotranspiration & $666 \%(2,000 \mathrm{~mm})$ & $288 \%(1,500 \mathrm{~mm})$ & $608 \%(1,400 \mathrm{~mm})$ \\
\hline
\end{tabular}

${ }^{1}$ Laterflow plus evapotranspiration (\%) $=\%$ infiltration - \% stored infiltration - \% seepage

\subsubsection{The importance of vegetation}

The appropriate choice and sustainability of vegetation on the cover is essential to its effectiveness in limiting seepage. The cover reported within this study was seeded and has only now become established in part due to dryer than expected conditions experienced at the mine over the past 1.5 to 2 years. However, the benefit of vegetation is noticeable in years 2 and 3 with the seepage from the cover reducing from $8 \%$ in year 1 to $<8 \%$ in years 2 and 3 . Species selection and seeding density are also being refined to achieve greater density and diversity of species. The long-term performance of the cover is expected to improve as the roots from vegetation reach the perched water table above the RPL $(2.2 \mathrm{~m} \mathrm{bgl})$, increasing the evapotranspiration rate and depth of influence of vegetation within the soil-mulch of the cover.

\section{Conclusion}

The mine has demonstrated through instrumentation that the cover has the potential to address the possible future release of saline drainage. The cover has wetted and dried out in response to rainfall and subsequent dry periods with some infiltration becoming seepage. After three years the cover seepage has decreased and is now below $8 \%$ of cumulative rainfall. Actual evapotranspiration far exceeds the mass balanced potential lateral flow plus evapotranspiration. Therefore lateral flow is likely only occurring in response to storm events where the vertical saturated hydraulic conductivity of the infiltration storage layer is quickly exceeded by the lateral saturated hydraulic conductivity, resulting in infiltration flowing laterally along the surface of the RPL before being discharged at the SWRD batter slopes. During periods of normal rainfall or during periods of no rainfall, all infiltration will initially infiltrate and then be removed by evapotranspiration $(\leq 86.35 \%)$. It is anticipated that the performance of the cover will improve as vegetation becomes established.

It is clear that the early performance of the cover is very much dependent on how quickly vegetation can establish. The vegetation establishment has been slow and it will take several years for the likely cover long-term water balance to become apparent. There is a need, therefore, to maintain monitoring for the order of 10 years to assess the cover at equilibrium under a range of climatic conditions. 


\section{References}

Allen, R, Jensen, M, Wright, J \& Burman, R 1989, 'Operational estimates of reference evapotranspiration', Agronomy Journal, vol. 81, pp. 650-662.

Ayres, B, Silveria, C, Ellice, C, Christenson, D \& O'Kane, M 2003, 'Development of a Cover System Design for Potentially Acid-Forming Tailings at Peak Gold Mine', in AB Fourie \& M Tibbett (eds), Proceedings of the Sixth International Conference on Mine Closure, Australian Centre for Geomechanics, Perth, pp. 957-963.

Campbell Scientific Inc 2000, On-Line Estimation of Grass Reference Evapotranspiration with the Campbell Scientific Automated Weather Station, viewed 12 October 2015, ftp://ftp.campbellsci.com/pub/outgoing/apnotes/evap.pdf

Cook, PG, Leaney, FW \& Miles, M 2004, 'Groundwater recharge in the north-east Mallee Region, South Australia', CSIRO land and water Technical report no. 25/04.

Defferrard, PL, Rohde, TK \& Lord, M 2015, 'Instrumentation and early monitoring results of the South Waste Rock Dump at Century mine', in AB Fourie, M Tibbett, L Sawatsky \& D. van Zyl (eds), Proceedings of the Tenth International Conference on Mine Closure, InfoMine, pp. 917-928.

Durham, A 2002, Design and Optimization of Waste Rock Cover Systems For Arid Environments, in Department of Civil Engineering, Master of Science, University of Saskatchewan, Saskatoon.

GARD Guide 2009, Global Acid Rock Drainage Guide, viewed 12 October 2015, www.gardguide.com

Geoslope 2012, Vadose Zone Modelling with VADOSE/W, viewed 12 October 2015, http://www.geo-slope.com/ products/vadosew.aspx

O'Kane, M \& Walters, P 2003, 'Dry Trial covers at Mt Whaleback - A Summary of Overburden Storage Area Cover System Performance', in AB Fourie \& M Tibbett (eds), Proceedings of the Sixth International Conference on Mine Closure, Australian Centre for Geomechanics, Perth, pp. 147-153.

O'Kane, M, Porterfield, D \& Weir, A 2000, 'Cover System Performance in a Semi-Arid Climate on Horizontal and Sloped Waste Rock Surfaces', in unknown (eds), Proceedings of Fifth International Conference on Acid Rock Drainage, pp. 1309-1317.

Rohde, TK 2012, Century Mine - As Built Cover Instrumentation, SKM consulting report for MMG Century Mine.

Rohde, TK \& Williams, DJ 2009, 'Early Hydrological Monitoring of Cadia's Instrumented Trial Waste Rock Dump', in Proceedings of Eighth International Conference on Acid Rock Drainage, Skellefteå, CD Publication.

Rohde, TK, Williams, DJ \& Burton, J 2011, 'Store and release cover performance at Cadia Hill gold mine, Australia', in AB Fourie \& $M$ Tibbett (eds), Proceedings of the Sixth International Conference on Mine Closure, Australian Centre for Geomechanics, Perth, pp. 333-343.

Russell, J \& Greacen, E 1977, Soil Factors in Crop Production in a Semi-arid Environment, University of Queensland Press, St Lucia.

Scott, P \& Defferrard, PL 2013, 'Quantifying Reactive Waste Rock Distribution In a Constructed Rock Storage Facility for Effective Closure', in L Kerr (ed.), Proceedings of the 2013 Workshop on Australian Mine Rehabilitation, Adelaide, JKTech Pty Ltd, pp. 9-13.

Williams, DJ 2008a, As-Built Report - South Dump Stage 1 Cover, Uniquest consulting report for MMG Century Mine.

Williams, DJ 2008b, Field and Laboratory Testing of Trafficed Shale, Uniquest consulting report for MMG Century Mine.

Williams, DJ, Stolberg, DJ \& Currey, NA 2006, 'Long-term performance of Kidston's "store/release" cover system over potentially acid forming waste rock dumps', in RI Barnhisel (ed.), Proceedings of Seventh International Conference on Acid Rock Drainage, American Society of Mining and Reclamation, pp. 2385-2396.

Williams, DJ, Wilson, G \& Currey, N 1997, 'A cover system for potentially acid forming waste rock dump in a dry climate', in unknown (eds), Proceedings of the Fourth International Conference on Tailings and Mine Waste, pp. 231-235.

Wilson, G 2000, 'Appropriate concepts and Criteria for the Design and Construction of Mine Waste Cover Systems', in NK Grundon \& LC Bell (eds), Proceedings of Fourth Australian Workshop on Acid Mine Drainage. 
